\title{
Relationship between Depression and Stress-Coping Strategies in Public Enterprise Workers Whose Workplaces Were Relocated to a New Environment
}

\author{
Minah Joo, MD, Bo-Hyun Yoon, MD, PhD, Jye-Heon Song, MD, Kyungmin Kim, MD, \\ Hangoeunbi Kang, MD, Suhee Park, MD, Yuran Jeong, MD, Hyunju Yun, MD, Jongtae Lee, MD, \\ Koosang Choi, MD \\ Department of Psychiatry, Naju National Hospital, Naju, Korea
}

\begin{abstract}
Background: In this study, the relationship between depression and stress-coping strategies among public enterprise workers whose workplaces were relocated to a newly-built innovation city was investigated.

Methods: This study included a total of 922 public enterprise workers living in Naju Innovation City. Along with their sociodemographic data, each subject was assessed concerning depression, occupational stress, and stress-coping strategies using the Center for Epidemiologic Studies Depression Scale(CES-D), Korean Occupational Stress Scale (KOSS), and stress-coping scale (SCS), respectively. Logistic regression was performed to investigate the impact of the relevant factors on depressive symptoms.

Results: The overall prevalence of depressive symptoms was $14 \%$. Some sociodemographic variables, the total scores of the KOSS, and four subscales of the SCS revealed significant differences between the depressed and normal groups. Multivariate regression analysis revealed that the KOSS (odds ratio [OR], $1.17 ; p<0.001$ ) and SCS, such as problem-solving-focused (OR, $0.75 ; p<0.001)$, emotion-focused $(O R, 1.15 ; p<0.05)$, and wishful-thinking-focused $(\mathrm{OR}, 1.10 ; \mathrm{p}<0.05)$, were significantly associated with depression.

Conclusion: The results indicated that depressive symptoms were highly prevalent among workers whose workplaces were relocated. In addition, these symptoms were found to be related with occupational stress and stress-coping strategies. Our findings also suggest that promoting healthy stress-coping strategies and reducing occupational stress may help in preventing the occurrence of depression and managing depressed workers.
\end{abstract}

Keywords Depressive symptoms; Workers; Occupational stress; Coping skills

\section{INTRODUCTION}

In Korea, the "Special Act on Balanced National Development" was implemented to ensure equal development between regions. A total of 10 innovation cities have been created nationwide since 2013, and public institutions concentrated in the metropolitan area are being dispersed and relocated to each region [1]. As a result, large numbers of employees in the target public enterprises are being transferred from metropolitan areas to rural areas in a short period of time. There are approximately 32,000 employees (based on the head office quota) from 175 public enterprises that are relocating to rural areas, and 4,618 are from institutions relocating

Received October 13, 2021, Revised October 28, 2021, Accepted November 1, 2021

Correspondence: Bo-Hyun Yoon, MD, PhD

Department of Psychiatry, Naju National Hospital, 1328-31, Senam-ro, Sanpo-myeon, Naju 58213, Korea

TEL +82-61-330-4102 FAX +82-61-330-4155 E-mail yoonbh@chollian.net ORCID https://orcid.org/0000-0002-3882-7930

Co-Correspondence: Jye-Heon Song, MD

Department of Psychiatry, Naju National Hospital, 1328-31, Senam-ro, Sanpo-myeon, Naju 58213, Korea

TEL +82-61-330-4182 FAX +82-61-330-4150 E-mail jhsong717@hanmail.net ORCID https://orcid.org/0000-0001-7370-519X

Copyright $\odot$ by Korean Society for Affective Disorders.

This is an Open Access article distributed under the terms of the Creative Commons Attribution Non-Commercial License (http://creativecommons.org/licenses/ by-nc/4.0/) which permits unrestricted non-commercial use, distribution, and reproduction in any medium, provided the original work is properly cited. 
to Gwangju and Jeonnam Join Innovation City (Naju Innovation City) [1]. Relocation to a newly built place of work can lead to high psychological anxiety from adapting to a new environment, the loss of personal ties formed in the previous location, and significant time needed to form new relationships, which may further increase people's psychological pain [2]. In a study conducted on workers who were relocated during the development of innovation cities, depression was high, and those who were depressed showed higher job stress and anxiety than non-depressed workers [3].

Depression has a higher socioeconomic burden than other major physical diseases [4]. In particularly, depression in workers leads to decreased work efficiency, loss of self-esteem, and decreased quality of life, which cause complex and serious damage to businesses and indirect social costs including decreased corporate productivity [5]. In a 2002 Canadian community health survey, $3.7 \%$ of workers between the age of 25 and 64 had experienced depression in the past year, and the prevalence of depression was higher in women (5.1\%) than in men $(2.6 \%)$ [6]. According to the US National Comorbidity Study, $6.4 \%$ of workers satisfied the criteria of depression in the past year, suggesting that depression was common in workers [7]. In Korea, $7.4 \%$ of office workers have been diagnosed with depression by medical professionals at least once in their lifetime [8], which is the same as the lifetime prevalence of depression in the total Korean population (7.4\%; major depressive disorder: $6.7 \%$, dysthymia: $0.7 \%$ ) [9]. According to the World Health Organization (WHO), depression accounts for $4.3 \%$ of the global disease burden. By 2030, it is predicted that depression will be the leading disease burden in developed countries [10]. Therefore, it is essential to identify and treat the causative factors of depression in workers as part of strategies for the prevention of depression.

Previous studies showed differences in the severity of depression among workers according to socioeconomic characteristics such as sex, age, education level, and income level [11-13], and reported that health influencing behaviors including smoking, diet, and drinking were important determinants on depression [11,14]. Therefore, to systematically identify factors affecting depression in workers relocating to new workplaces, this study analyzed how sociodemographic factors affect depression and investigated the relationships between job stress, coping with stress, and depressive symptoms. In Korea, many studies have assessed the prevalence and conditions of depressive disorder in the general population $[7,11,15]$, and several studies have evaluated the quality of life and depression of residents whose living environment has changed due to national policies [16]. However, there is a lack of studies on depression in workers after the relocation of public institutions by law. Therefore, the purpose of this study was to identify the prevalence and related factors of depression in public enterprise workers whose workplaces were relocated to the newly built Naju Innovation City and to provide basic data on depression and stress management among said workers.

\section{MATERIALS AND METHODS}

\section{Subjects}

This study was conducted on workers in Naju Innovation City from April to May 2019. Samples were extracted using a proportional allocation method, and a questionnaire was conducted through individual interviews by professional investigators with employees who agreed to participate in the study. The participants were given an explanation about the purpose of the survey, and directions were provided to help the participants answer the survey questionnaires, which included several self-report screening instruments.

A total of 982 questionnaires were collected, and data were extracted from 922 questionnaires for the final analysis, after excluding 60 that were not completed. This study was approved by the Institutional Review Board of Naju National Hospital (approval number: NNH-HR-2020-9).

\section{Design and assessment}

\section{1) Sociodemographic characteristics}

Sociodemographic characteristics such as sex, age, length of employment, marital status, living with family, alcohol use, satisfaction with residential life, and overall satisfaction with life in Naju Innovation City were evaluated. Marital status was divided into married and unmarried (single, divorced, and separated). For investigation of whether living with family, participants were divided into groups living and not living with their families (weekend couple, single). Alcohol use was assessed using the first item of the Korean version of the 
Alcohol Use Disorders Identification Test (AUDIT-K) to divide the participants into groups of alcohol consumers and non-consumers (Table 1).

\section{2) The Center for Epidemiologic Studies Depression Scale (CES-D)}

Depressive symptoms were evaluated using the CES$\mathrm{D}$, which was originally developed by the American Institute of Mental Health [17]. The CES-D evaluates the frequency and severity of six typical symptoms of depression in the past week: depressed mood, guilt or worthlessness, hopelessness, psychomotor retardation, loss of appetite, and sleep disorder. The scale emphasizes the emotional and psychological aspects of depression [17]. The Korean version of the CES-D consists of 28 items, which are evaluated on a 4-point Likert scale, with the total score ranging from 0 to 84 points. A higher score indicates a higher likelihood of depression [18]. As previous studies described, the total score of 21 was used as the cut-off with a sensitivity of $95.7 \%$ and specificity of $69.5 \%$, which was useful for screening significant depressive symptoms in the general population.

Table 1. General characteristics between depressed and normal public enterprise workers whose workplace was relocated to Naju Innovation City

\begin{tabular}{|c|c|c|c|c|}
\hline Variable & Depressed $(n=131)$ & Normal $(n=791)$ & $\chi^{2}$ & $p$-value \\
\hline Sex & & & 5.22 & $<0.05$ \\
\hline Male & $74(56.5)$ & $528(66.8)$ & & \\
\hline Female & $57(43.5)$ & $263(33.2)$ & & \\
\hline Age (y) & & & 3.59 & 0.465 \\
\hline $20-29$ & $37(28.2)$ & $192(24.3)$ & & \\
\hline $30-39$ & $53(40.5)$ & $285(36.1)$ & & \\
\hline $40-49$ & $27(20.6)$ & $209(26.4)$ & & \\
\hline $50-59$ & $11(8.4)$ & $88(11.1)$ & & \\
\hline$\geq 60$ & $3(2.3)$ & $17(2.1)$ & & \\
\hline Length of employment (y) & & & 5.20 & 0.392 \\
\hline$<1$ & $7(5.3)$ & $44(5.6)$ & & \\
\hline $1-5$ & $78(59.6)$ & $432(54.6)$ & & \\
\hline $6-10$ & $21(16.0)$ & $101(12.8)$ & & \\
\hline $11-15$ & $6(4.6)$ & $76(9.6)$ & & \\
\hline $16-20$ & $8(6.1)$ & $61(7.7)$ & & \\
\hline$>20$ & $11(8.4)$ & $77(9.7)$ & & \\
\hline Marital status & & & 6.35 & $<0.05$ \\
\hline Married & $56(42.7)$ & $432(54.6)$ & & \\
\hline Unmarried & $75(57.3)$ & $359(45.4)$ & & \\
\hline Living with family & & & 6.20 & $<0.05$ \\
\hline Yes & $30(22.9)$ & $268(33.9)$ & & \\
\hline No & $101(77.1)$ & $523(66.1)$ & & \\
\hline Alcohol use & & & 0.03 & 0.872 \\
\hline Yes & $112(85.5)$ & $672(85.0)$ & & \\
\hline No & $19(14.5)$ & $119(15.0)$ & & \\
\hline Satisfaction with residential life & & & 16.60 & $<0.001$ \\
\hline Satisfied & $43(32.8)$ & $411(52.0)$ & & \\
\hline Usually satisfied & $53(40.5)$ & $236(29.8)$ & & \\
\hline Dissatisfied & $35(26.7)$ & $144(18.2)$ & & \\
\hline Overall satisfaction & & & 21.27 & $<0.001$ \\
\hline Satisfied & $24(18.3)$ & $281(35.5)$ & & \\
\hline Usually satisfied & $57(43.5)$ & $332(42.0)$ & & \\
\hline Dissatisfied & $50(38.2)$ & $178(22.5)$ & & \\
\hline
\end{tabular}

Values are presented as number (\%). 
Participants having scores more than 21 were classified as the depressive symptom group [18].

\section{3) Korean Occupational Stress Scale (KOSS)}

The KOSS was used to measure the occupational stress of the participants [19]. The tool consists of eight domains: physical environment, job demands, insufficient job control, interpersonal conflict, job insecurity, organizational system, lack of reward, and occupational climate, with a total of 43 items. Each item is evaluated on a 4-point Likert scale ranging from "strongly disagree" to "strongly agree." Each domain's score is converted into a score out of 100 points, and the sum of all scores is used to assess occupational stress. In this study, a score higher than the median value of the enterprise or higher than the reference value of worker occupational stress suggested by the Korea Occupational Safety and Health Agency (KOSHA CODE H-42-2006) indicated that the participant was exposed to relatively more factors of occupational stress compared to the normal group [20].

\section{4) Stress-coping scale}

The stress-coping scale developed by Lazarus and Folkman consists of 68 items [21] and is used to evaluate stress-coping in daily life. The tool was adapted, revised, and supplemented by Lee and Kim [19] to consist of 62 items under 4 factors: problem-solving-focused stress-coping, seeking social support, wishful thinking, and emotion-focused stress-coping. Each item is evaluated on a 4-point Likert scale ranging from "not at all" to "very much." In a study on the relationship between $\mathrm{A}$ and B personality types, self-identity, and coping with stress [22], a total of 24 items with 6 items from each of the 4 factors were selected. Problem-solvingfocused stress-coping and seeking social support were conceptualized as active coping, and wishful thinking and emotion-focused stress-coping were conceptualized as passive coping. A higher score for active coping suggested that the participants relied more on active coping, and a higher score for passive coping indicated that the participants used more passive coping for stress-coping. The Cronbach's $\alpha$ value of previous study was 0.81 [22]. The Cronbach's $\alpha$ in this study was 0.82 , and the individual Cronbach's $\alpha$ for problem-solving-focused stresscoping, seeking social support, wishful thinking, and emotion-focused stress-coping were $0.75,0.74,0.62$, and 0.73 , respectively.

\section{Statistical analysis}

Using a cut-off score of 21 on the CES-D, participants were divided into those with and without depressive symptoms which labelled as depression and normal group, respectively. To identify factors affecting depression, differences in sociodemographic characteristics and scale scores according to depression were assessed using the chi-square test and independent t-test. A multivariate logistic regression analysis was conducted using variables that had significant relationships with depressive symptoms in the univariate analysis. The collected data were statistically analyzed using IBM SPSS Statistics for windows, version 21.0 (IBM Corp., Armonk, NY, USA) and a p-value $<0.05$ was considered statistically significant.

\section{RESULTS}

\section{Prevalence of depression and related sociodemographic characteristics}

A total of 131 participants $(14 \%$ of the total participants) were included in the depression group. Seventyfour male (12.3\%) and fifty-seven female (17.8\%) were in the depression group, showing that the prevalence of depression was significantly higher in female $\left(\chi^{2}=5.22\right.$, $\mathrm{p}<0.05)$. The prevalence of depressive symptoms was $11.5 \%$ in married participants and $17.3 \%$ in unmarried participants, a significant difference $\left(\chi^{2}=6.35, \mathrm{p}<0.05\right)$. The prevalence of depressive symptoms was $10.1 \%$ in participants who were living with family and $16.2 \%$ in those who did not live with family, also a significant difference $\left(\chi^{2}=6.20, p<0.05\right)$. Also, significant differences were found on the variables such as the satisfaction with residential life $\left(\chi^{2}=16.60, p<0.001\right)$ and the satisfaction with their overall life in Naju Innovation City $\left(\chi^{2}=21.27\right.$, $\mathrm{p}<0.001)$. There were no significant differences according to age, length of employment, and alcohol use (Table 1).

\section{Comparison of psychosocial variables between the depression and normal groups}

The mean score of the CES-D in the depression group was $28.89 \pm 7.48$, which was significantly higher compared to $8.01 \pm 5.08$ in the normal group ( $\mathrm{t}=-30.81$, $\mathrm{p}<0.001)$. The mean score of the KOSS in the depression 
group was $49.87 \pm 9.71$, which was significantly higher than the $38.48 \pm 8.49$ in the normal group $(\mathrm{t}=-13.93$, $\mathrm{p}<0.001)$. Compared to the normal group, the depression group had a lower problem-solving-focused stresscoping score $(\mathrm{t}=8.84, \mathrm{p}<0.001)$ and lower seeking social support score $(\mathrm{t}=4.34, \mathrm{p}<0.001)$. Additionally, compared to the normal group, the depression group had higher scores for emotion-focused stress-coping ( $\mathrm{t}=-3.47$, $\mathrm{p}<0.05)$ and wishful thinking $(\mathrm{t}=-2.21, \mathrm{p}<0.05)($ Table 2$)$.

\section{Factors affecting depressive symptoms}

To find factors affecting the depressive symptoms of workers whose workplaces were relocated to an innovation city, a multivariate logistic regression analysis was conducted using variables that were significant in the simple analysis as independent variables. The depression and normal groups divided based on CES-D score were set as the dependent variables. As a result, a high total score on the KOSS increased the likelihood of developing depressive symptoms by 1.17 times $(95 \%$ confidence interval [CI], 1.13-1.21; $\mathrm{p}<0.001)$. Problem-solving-focused stress-coping, which is an active coping strategy, acted as a protective factor that lowered the likelihood of developing depression by 0.75 times $(95 \%$ CI, $0.67-0.84$; $\mathrm{p}<0.001)$. In contrast, passive coping strategies such as emotion-focused stress-coping increased the likelihood of depressive symptoms by 1.15 times (95\% CI, 1.04 $1.28 ; \mathrm{p}<0.05)$. Additionally, wishful thinking was another risk factor that increased the likelihood of depressive symptoms by 1.10 times ( $95 \% \mathrm{CI}, 1.00-1.20 ; \mathrm{p}<0.05)$. Sex, marital status, living with family, satisfaction with residential life, and overall satisfaction with life in Naju Innovation City did not have significant effects on de- pressive symptoms (Table 3 ).

\section{DISCUSSION}

This study was conducted to assess the prevalence of depression and analyze psychosocial factors in public enterprise workers who relocated to Naju Innovation City.

The prevalence of depression in workers was $14 \%$. In a previous study of 998 employees who underwent general checkups at the Corporate Mental Health Research Center at Kangbuk Samsung Hospital (Seoul, Korea), the prevalence of depression was $6.2 \%$ [23]. In another study of 194,226 participants that conducted general checkups at the Comprehensive Medical Examination Center (Seoul, Suwon), the prevalence of depression was $5.7 \%$ [23]. In both studies, the prevalence was lower than that observed in our study. In another study conducted in 2015 , approximately $7.4 \%$ of 1,000 Korean office workers had been diagnosed with depression by a medical professional at least once in their lifetime [8], which was lower than that observed in our study. Although that study was conducted on office workers as in our study, the Impact of Depression at Work Audit was used as the diagnostic tool compared to the CES-D in this study [8]. In other countries, the prevalence of depressive symptoms in workers was $3.7 \%$ to $6.4 \%$ [6,7], which was lower than that in our study. Overall, the prevalence of depression in office workers in our study was higher than that in previous studies. The relocation of a workplace causes changes in job characteristics and interpersonal relationships. Adapting to a new environment may lead to increased stress, which may cause more depres-

Table 2. Comparisons of mental health-related conditions among subjects with and without depression in public enterprise workers whose workplace was relocated to Naju Innovation City

\begin{tabular}{|c|c|c|c|c|}
\hline Variable & Depressed $(n=131)$ & Normal $(n=791)$ & $\mathrm{t}$ & $p$-value \\
\hline CES-D, score & $28.89 \pm 7.48$ & $8.01 \pm 5.08$ & -30.81 & $<0.001$ \\
\hline KOSS, score & $49.87 \pm 9.71$ & $38.48 \pm 8.49$ & -13.93 & $<0.001$ \\
\hline \multicolumn{5}{|l|}{ Stress-coping ${ }^{a}$} \\
\hline Problem solving & $14.58 \pm 2.82$ & $16.99 \pm 2.90$ & 8.84 & $<0.001$ \\
\hline Social support & $14.59 \pm 2.98$ & $15.87 \pm 3.15$ & 4.34 & $<0.001$ \\
\hline Emotion focused & $12.98 \pm 2.78$ & $12.16 \pm 2.49$ & -3.47 & $<0.05$ \\
\hline Wishful thinking & $15.18 \pm 3.44$ & $14.53 \pm 3.07$ & -2.21 & $<0.05$ \\
\hline
\end{tabular}

Values are presented as mean \pm standard deviation.

CES-D, Center for Epidemiologic Studies Depression Scale; KOSS, Korean Occupational Stress Scale.

${ }^{a}$ Stress-coping scale (SCS) was used which revised by Park [19] based upon the work of Lazarus and Folkman [21]. 
Table 3. Logistic regression analysis for the factors affecting depressive symptoms

\begin{tabular}{|c|c|c|c|c|c|}
\hline Variable & B & SE & Wals & $\mathrm{p}$-value & OR $(95 \% \mathrm{Cl})$ \\
\hline KOSS & 0.15 & 0.02 & 77.03 & $<0.001$ & $1.17(1.13-1.21)$ \\
\hline \multicolumn{6}{|l|}{ Stress-coping } \\
\hline Problem solving & -0.29 & 0.06 & 27.02 & $<0.001$ & $0.75(0.67-0.84)$ \\
\hline Social support & 0.06 & 0.05 & 1.39 & 0.238 & $1.06(0.96-1.17)$ \\
\hline Emotion focused & 0.14 & 0.05 & 7.14 & $<0.05$ & $1.15(1.04-1.28)$ \\
\hline Wishful thinking & 0.09 & 0.05 & 3.91 & $<0.05$ & $1.10(1.00-1.20)$ \\
\hline \multicolumn{6}{|l|}{ Sex } \\
\hline Female & -0.02 & 0.25 & 0.01 & 0.945 & $0.98(0.61-1.59)$ \\
\hline \multicolumn{6}{|l|}{ Marital status } \\
\hline Unmarried & 0.11 & 0.29 & 0.13 & 0.714 & $1.11(0.63-1.95)$ \\
\hline \multicolumn{6}{|l|}{ Living with family } \\
\hline No & 0.58 & 0.33 & 3.06 & 0.080 & $1.79(0.93-3.43)$ \\
\hline \multicolumn{6}{|c|}{ Satisfaction with residential life } \\
\hline Satisfied & -0.36 & 0.38 & 0.90 & 0.343 & $0.70(0.33-1.47)$ \\
\hline Usually satisfied & 0.15 & 0.37 & 0.16 & 0.692 & $1.16(0.56-2.39)$ \\
\hline Dissatisfied & & & 3.59 & 0.166 & \\
\hline \multicolumn{6}{|l|}{ Overall satisfaction } \\
\hline Satisfied & 0.23 & 0.40 & 0.34 & 0.558 & $1.26(0.58-2.74)$ \\
\hline Usually satisfied & 0.36 & 0.33 & 1.18 & 0.277 & $1.43(0.75-2.74)$ \\
\hline Dissatisfied & & & 1.21 & 0.546 & \\
\hline
\end{tabular}

B, unstandardized beta coefficients; SE, standard error; OR, odds ratio; Cl, confidence interval; KOSS, Korean Occupational Stress Scale. OR was calculated using a logistic regression analysis.

sive symptoms [3]. Previous studies have consistently reported depressive symptoms in immigrant workers and immigrants. In a study of 3,113 Mexican immigrants in the USA, $13.3 \%$ had a score of 16 or higher for CES$\mathrm{D}$ depressive symptoms [24]. In another study, $61.3 \%$ of 299 Moroccan and 33.3\% of 304 Turkish immigrant workers in the Netherlands had severe depressive symptoms with a CES-D score higher than 16 points [25]. In Korea, approximately $29 \%$ of 64 North Korean defectors had depressive symptoms with a CES-D score of 21 points or higher [26]. Our findings are in agree with those of previous studies, suggesting that the severity of depression varies according to the relocation of workplaces and residences.

We observed that occupational stress increased the risk of depression even after correcting for the effects of other factors through multivariate analysis. This was consistent with the findings of previous studies in which occupational stress factors were related to depression in various groups of workers [27]. Individuals unsuitable for the work environment suffer from severe occupational stress, which causes negative emotions such as depression and anxiety [28]. In contrast, another study reported that depression has negative effects on occupational stress [29]. Future prospective studies must investigate the causal relationship between depression and occupational stress. According to a study conducted on public enterprise workers who relocated to Naju Innovation City in 2017, factors related to depressive symptoms were the variables such as dissatisfaction with overall life in the Innovation City, no alcohol use, unmarried marital status, and high scores on state anxiety [3]. While the stresses caused by environmental factors were highly influenced to depression in the early stage of relocation [3], the occupational stress might have impact on depression in this study. Therefore, adequate management of occupational stress is important in preventing depression.

The early concepts of occupational stress-induced depression focused on the physical environment and physical safety of workers during work [30]. However, psychological health promotion programs focused on the behavior and lifestyle of workers can greatly contribute to reducing occupational stress and preventing depression $[30,31]$. In the stress-vulnerability model, stress can trigger potential vulnerability factors, causing depres- 
sion; however, adequate coping methods for stress can help individuals maintain an adaptive state [32]. This suggests that although stress, an environmental factor, can directly cause psychological maladaptation, an individual's intrinsic factors play an important role in coping with stress. In a previous study on the mediating effects of stress-coping, problem-solving-focused stress-coping and emotion-focused stress-coping played a mediating role between stress and depressive symptoms [32]. Furthermore, stress affected depression and suicidal thoughts through passive coping [33].

In our study, we observed that problem-solving-focused stress-coping, which is an active coping strategy, lowered the risk of depressive symptoms acting as a protective factor, while passive stress-coping strategies increased the risk. We confirmed a negative relationship between problem-solving-focused stress-coping and depression, and our findings are partly consistent with those of previous studies [34] in which more active coping strategies led to greater psychological wellbeing. Problem-solving-focused stress-coping is an active and positive coping method in which the individual confronts difficulties during adaptation processes and seeks out resources with the determination to solve the problem [34]. Therefore, problem-solving-focused stress-coping may have contributed to the management of stress caused by involuntary relocation, thereby lowering depressive symptoms.

Emotion-focused stress-coping and wishful thinking, which are passive coping methods, were positively related with depressive symptoms, suggesting that passive stress-coping strategies are ineffective and lead to negative results. Passive stress-coping consists of strategies to avoid thinking about or experiencing stressful situations [35]. These strategies may help to temporarily reduce negative emotions; however, in the long term, these may not be effective in the management of emotions and cause psychological difficulties [35]. Therefore, it would be helpful to check the coping methods related to the maladaptive emotional reactions experienced by relocated public enterprise workers and to train them to use more effective active coping strategies to reduce depression and promote their psychological well-being.

Lazarus and Folkman [21] reported that problemsolving-focused stress-coping is often used when people perceive that stress can be changed, while emotionfocused stress-coping is used when they perceive that it cannot be changed. In a study investigating the moderat- ing effects of problem-solving-focused stress-coping on the relationship between stress and depression [36], in low-stress situations, increased problem-solving-focused stress-coping lowered depression. When the stress level was increased, the decrease in depression was relatively small, such that problem-solving-focused stress-coping had counter-buffering effects. As such, stress-coping strategies may have different effects depending on the stress level or situation. Here, different levels of stress were not analyzed. Future studies must assess the relationship between depression and stress-coping according to the level of stress.

Several limitations must be considered in the interpretation of our research findings. First, questionnairebased data were used in this study, and the results depended on the self-reports of the participants. The mental health professionals were not actively engaged in the diagnostic interview with participants in this study, so the prevalence of depression may not be accurately interpreted. Second, this study was only conducted on public enterprise workers who relocated to an innovation city. Thus, the findings cannot be generalized. Future studies must assess different workers in various occupations for a comprehensive understanding. Third, as this was a cross-sectional study, the causal relationship between related factors and depressive symptoms cannot be accurately explained. In particularly, there was no questionnaire data that could be used to identify the specific causal relationships such as the length of employment in the innovation city and voluntary relocation. In the future, systematic prospective studies must be conducted to identify causality.

However, this study is meaningful as it investigated the prevalence of depression in public enterprise workers who relocated to Naju Innovation City and showed the impact of job stress and stress-coping strategies on depression. Previous studies investigated the prevalence of depression in the general population and workers within the scope of daily life $[5,12]$. However, only a limited number of studies systematically examined the problems that may arise when public enterprises located in metropolitan areas are moved to the 10 innovation cities nationwide in accordance with the "Special Act on Balanced National Development" for balanced development among regions, as in this study [1]. In future studies, it may be clinically important to systematically investigate the psychiatric problems that may be observed in workers who relocated to a new environment. Additionally, 
our findings may be actively utilized in Employee Assistance Program (EAP) for workers whose workplaces were relocated.

\section{CONCLUSION}

This study investigated the relationships between depressive symptoms and occupational stress, and stresscoping strategies in public enterprise workers who relocated to Naju Innovation City. The prevalence of depression in workers assessed using the CES-D was $14 \%$, and this was higher than that of the general population. Variables such as sex, marital status, living with family, the satisfaction with residential life, and the overall satisfaction with life in Naju Innovation City revealed significant differences between the depression and normal groups. Occupational stress was higher in the depressed than in the normal group. Additionally, compared to the normal group, the depression group used less active stress-coping strategies and more passive stress-coping strategies. A high total score on the KOSS was also a factor affecting to depressive symptoms.

These results suggest that the prevalence of depressive symptoms is high in public enterprise workers who relocated to Naju Innovation City and depressive symptoms are related to occupational stress and stress-coping strategies. The findings of this study may be used as basic data to implement EAP.

\section{CONFLICTS OF INTEREST}

The authors have nothing to disclose.

\section{ORCID}

Minah Joo
https://orcid.org/0000-0002-2330-5320
Bo-Hyun Yoon
https://orcid.org/0000-0002-3882-7930
Jye-Heon Song
https://orcid.org/0000-0001-7370-519X
Kyungmin Kim
https://orcid.org/0000-0001-5376-1418
Hangoeunbi Kang
https://orcid.org/0000-0002-7106-2757

\author{
Suhee Park \\ https://orcid.org/0000-0002-7366-8226 \\ Yuran Jeong \\ https://orcid.org/0000-0002-0087-0992 \\ Hyunju Yun \\ https://orcid.org/0000-0002-6792-7762 \\ Jongtae Lee \\ https://orcid.org/0000-0002-9033-501X \\ Koosang Choi \\ https://orcid.org/0000-0003-4885-7452
}

\section{REFERENCES}

1. Lee JR. The national and region effect for establishment of innovation city. Planning of Policy 2006;297:39-48.

2. Gaylord M, Symons E. Relocation stress: a definition and a need for services. Empl Assist Q 1986;2:31-6.

3. Kang H, Yoon BH, Jeon BH, Kim HY, Sea YH, Song JH, et al. Depressive symptoms and its related factors of the public enterprise workers who relocated to an innovation city. Mood Emot 2017;15:156-62.

4. Murray CJ, Lopez AD. Alternative projections of mortality and disability by cause 1990-2020: Global Burden of Disease Study. Lancet 1997;349:1498-504.

5. Bender A, Farvolden P. Depression and the workplace: a progress report. Curr Psychiatry Rep 2008;10:73-9.

6. Gravel R, Béland Y. The Canadian Community Health Survey: mental health and well-being. Can J Psychiatry 2005;50:573-9.

7. Kessler RC, Akiskal HS, Ames M, Birnbaum H, Greenberg P, Hirschfeld RM, et al. Prevalence and effects of mood disorders on work performance in a nationally representative sample of U.S. workers. Am J Psychiatry 2006;163:1561-8.

8. Hong JP, Lee DW, Sim YJ, Kim YH. Awareness, attitude and impact of perceived depression in the workplace in Korea. J Korean Neuropsychiatr Assoc 2015;54:188-201.

9. Cho MJ, Seong SJ, Park JE, Chung IW, Lee YM, Bae A, et al. Prevalence and correlates of DSM-IV mental disorders in South Korean adults: the Korean epidemiologic catchment area study 2011. Psychiatry Investig 2015;12:164-70.

10. World Health Organization. Global burden of mental disorders and the need for a comprehensive, coordinated response from health and social sectors at the country level. Geneva: World Health Organization; 2012.

11. Lee HJ, Kahng SK, Lee JY. The effects of socioeconomic position and health behavior on geriatric depressive symptom. J Korean Gerontol Soc 2008;28:1129-45.

12. Mudgal J, Guimaraes Borges GL, Díaz-Montiel JC, Flores Y, Salmerón J. Depression among health workers: the role of social characteristics, work stress, and chronic diseases. Salud Ment 2006;29:1-8.

13. Talala K, Huurre T, Aro H, Martelin T, Prättälä R. Socio- 
demographic differences in self-reported psychological distress among 25- to 64-year-old Finns. Soc Indic Res 2008;86:323-35.

14. Choi H, Lee H. The relations of problem drinking, depressive mood, and suicidal ideation among Korean workers. Korean Public Health Res 2016;42:29-40.

15. Kim SH, Kim JH, Jung HS, Park JC, Kim YS. Depressive symptoms among a group of medical students: prevalence, related factorsand moderating effect by the positive psychology. Mood Emot 2014;12:128-36.

16. Ko J. Relation of environment change in relation to national policy and quality of life of the elderly: focusing on the case of Ganjung in Jeju [Master's thesis]. Seoul: Ewha Womans University; 2015.

17. Radloff LS. The CES-D scale: a self-report depression scale for research in the general population. Appl Psychol Meas 1977;1:385-401.

18. Cho MJ, Kim KH. Use of the Center for Epidemiologic Studies Depression (CES-D) scale in Korea. J Nerv Ment Dis 1998;186:304-10.

19. Lee CH, Kim JH. Relations of perceived stress, cognitive set, and coping behaviors to depression: a focus on freshmen's stress experiences. Korean J Couns Psychother 1988;1:25-45.

20. Hwang HY, Kim HM, Kim IS, Son JS. A study on the job stress of opticians. J Korean Ophthalmic Opt Soc 2013;18:1-10.

21. Lazarus RS, Folkman S. Stress, appraisal, and coping. New York: Springer; 1984.

22. Park JY. A study on the relationship among character type A \& B ego-identity and stress coping [Master's thesis]. Seoul: Sookmyung Women's University; 1995.

23. Jung CH, Lim SW, Shin DW, Oh KS, Shin YC. Associations of overlapped job stress components with depressive symptoms and suicidal idea. Anxiety Mood 2017;13:32-8.

24. Alderete E, Vega WA, Kolody B, Aguilar-Gaxiola S. Depressive symptomatology: prevalence and psychosocial risk factors among Mexican migrant farmworkers in California. J Community Psychol 1999;27:457-71.
25. van der Wurff FB, Beekman AT, Dijkshoorn H, Spijker JA, Smits $\mathrm{CH}$, Stek ML, et al. Prevalence and risk-factors for depression in elderly Turkish and Moroccan migrants in the Netherlands. J Affect Disord 2004;83:33-41.

26. Han IY. Depressive traits of North Korean defectors. Ment Health Soc Work 2001;6:78-94.

27. Lee SW, Kim KS, Kim TG, Ryu HW, Lee MY, Won YL, et al. The relationship between job stress and depressive symptoms in migrant workers in Kyung-gi province in Korea. Korean J Occup Environ Med 2009;21:76-86.

28. Oh KO, Gang MH, Lee ST. Perceived occupational stress and depression of school nurses. J Korean Public Health Nurs 2012;26:60-71.

29. Yoon SH, Bae JY, Lee SW, An KE, Kim SE. The effects of job stress on depression, drinking and smoking among Korean men. Health Soc Sci 2006;19:31-50.

30. Shin YC. Job stress and depression. J Korean Neuropsychiatr Assoc 2020;59:88-97.

31. Grawitch MJ, Trares S, Kohler JM. Healthy workplace practices and employee outcomes. Int J Stress Manag 2007; 14:275-93.

32. Gong SJ, Lee EH. Mediation effect of coping between life stress and depression in female college students. Korean J Woman Psychol 2006;11:21-40.

33. Ha JH, An SH. The verification of a structural relationship model of suicidal ideation to stress, coping styles, perfectionism, depression, and impulsivity. Korean J Couns Psychother 2008;20:1149-71.

34. Kim CY. Self-differentiation, stress level and stress coping strategies of nursing students. J Korean Acad Soc Nurs Educ 2006;12:238-47.

35. Amirkha JH. A factor analytically derived measure of coping: The Coping Strategy Indicator. J Personal Soc Psychol 1990;59:1066-74.

36. Lee EH. Life stress and depressive symptoms among college students: testing for moderating effects of coping style with structural equations. Korean J Health Psychol 2004; $9: 25-52$. 